\title{
Effectiveness of Body Awareness Therapy in Stroke Survivors: A Systematic Review of Randomized Controlled Trials
}

This article was published in the following Dove Press journal: Open Access Journal of Clinical Trials

\section{Abayneh Alamer (D) \\ Kefale Getie (D) \\ Haimanot Melese iD \\ Habtamu Mazea \\ Department of Physiotherapy, School of Medicine, College of Health Sciences and Ayder Comprehensive Specialized Hospital, Mekelle University, Mekelle, Ethiopia}

Correspondence: Abayneh Alamer

Tel +2510922276256

Fax +251034441668I/91

Email abayphysio@gmail.com

\begin{abstract}
Body awareness therapy has been hypothesized as an effective program for maintaining balance and improving gait function in patients with neurological diseases. Nevertheless, there is a dearth of recent studies in a systematic way to confirm its efficacy on stroke survivors. The objective of this review was to synthesize the current evidence on the effectiveness of body awareness therapy on balance and gait function in stroke survivors. A comprehensive search of PubMed, CINAHL, AMED, PEDro, EMBASE, REHABDATA Database, and Scopus was done to identify randomized controlled trials of body awareness therapy in individuals with stroke. The PEDro scale was used to evaluate the methodological quality of included trials. The primary outcome measures of this review were the 10-Meter Walk Test (10MWT) and Berg Balance Scale (BBS). Due to varying included trials, metaanalysis was not carried out. Nine randomized controlled trials with 332 patients were analyzed. Body awareness therapy exhibited a moderate confirmation to better balance and gait function of stroke survivors. Body awareness therapy could be a well-founded rehabilitative intervention and might support enhanced balance and gait function of individuals with stroke.
\end{abstract}

Keywords: motor imagery training, body awareness training, systematic review, stroke, balance, gait function

\section{Introduction}

Stroke can produce visual-perceptual deficits, resulting from lesions of the parietal cortex. $^{1-3}$ The reported incidence of stroke-related visual-perceptual deficits ranges from $32 \%$ to $81 \%{ }^{1,4}$ Stroke might cause significant body scheme/body image and spatial relation disorders, and motor and sensory impairments, which potentially leads to different health problems, and compromised individuals' quality of life. ${ }^{5-7}$ Stroke survivors usually suffered postural control impairments that could be potentially affecting balance and gait function. ${ }^{8-10}$ As a result, stroke rehabilitative interventions are focused to enhance postural control, balance, and gait functioning for independence of daily activities for individuals with stroke. ${ }^{11,12}$ Thus, among numerous restorative approaches, body awareness therapy is considered to enhance balance and gait function in individuals with stroke by employing task-specific approaches. $^{13,14}$

Body awareness therapy (BAT) is a physiotherapeutic modality that examines a person's postural stability and focus to find a new attitude towards their body. ${ }^{15}$ Thus, it could strengthen the individual's recourses, integrating it in their daily 
living activities. In basic BAT the attention is both on the doing and on what is experienced in the movements, which in turn increase a self-awareness of physical, mental, and psychosocial aspects of body awareness. ${ }^{16}$ It is central to find the center line of the body by performing different movements like weight shifting and rotations, together with giving attention to the body. ${ }^{17,18}$ BAT is a strategy for enhancement of balance and postural control capacity by basic dreary developments that keep up capacity utilizing stability limits. ${ }^{15,19}$ This strategy has a taskspecific approach that comprises straightforward dreary developments that challenge a person's steadiness limits to upgrade an individual's mindfulness of their development and reflect upon how their body feels when performing the movements. ${ }^{20,21}$ The movements in body awareness therapy focus on balance and postural solidness that may well be useful for people with stroke.

Given the significance of BAT, its effectiveness in the treatment of balance and gait function among stroke survivors is not well known. To the extent of our knowledge, there is no systematic review done to evaluate the adequacy of body awareness therapy on balance and gait functions in subjects with stroke. Hence, the purpose of this review was to efficiently synthesize proof from randomized controlled trials on the effectiveness of body awareness therapy on balance and gait function in subjects with stroke.

\section{Methods}

\section{Design}

This systematic review was done and detailed in compliance with the Preferred Reporting Items for Systematic Reviews and Meta-Analyses (PRISMA) guideline. ${ }^{22}$

\section{Search Strategy}

A literature search was performed to recognize all qualified randomized controlled trials. An electronic search of the literature was conducted to identify relevant studies from the following databases: PubMed, CINAHL, AMED, PEDro, EMBASE, REHABDATA Database, and Scopus. The following terms were utilized as key words: "stroke/ cerebrovascular accident", "body awareness therapy", "balance", and "gait function". As subject headings shifted between the databases, various combinations of the key words were utilized as follows: "stroke/cerebrovascular accident", AND "body awareness training"/“body mind therapy"/“sensorimotor training"/"postural control training"/"modified sitting to standing training"/"motor imagery training", AND "balance/stability", AND "walking/gait/mobility", AND "randomized controlled trial". The retrieving of the studies was set from 2010 to May 2020 for the published articles.

\section{Eligibility Criteria}

Eligibility of each study was determined based on the PICO (population/problem(s), intervention(s), comparison(s), outcome(s)) standard. PICO refers to a well-focused clinical research question in terms of the specific patient problem and aids the searcher in finding clinically relevant evidence in the literature. ${ }^{23}$ This framework helps the clinician articulate the clinical question most applicable to the patient and facilitates the search process by identifying the key concepts for an effective search strategy. ${ }^{24,25}$ Studies searched were considered qualified in the case they met the following criteria: 1) population: studies with participants with stroke; 2) intervention: experimental groups received body awareness therapy; 3) comparison(s): control group received conventional physiotherapy; and 4) outcomes: balance, gait, walking speed, and functional status. All randomized controlled trials (RCTs) conducted to determine the effectiveness of body awareness training on stroke survivors were included in this review. Only full-text articles published in the English language were included. Observational studies and conference abstracts were excluded from this review. Adult individuals with acute, sub-acute, and chronic/late phase of stroke survivors with hemiplegia/hemiparesis were considered in this study. RCTs comparing the effectiveness of body awareness training with the conventional physiotherapy were included in this review. Conventional physiotherapy is an intervention (s) given to individuals with stroke which includes treadmill training, gait training, walking training, and usual daily activities.

\section{Study Selection}

Two reviewers (A.A. and K.G.) retrieved papers from the identified lists on the basis of title/abstract, based on the established criteria for inclusion. The studies were retrieved in detail through methodological quality and data extraction tools. The third reviewer (H.M.) was there to solve the disagreements between the two reviewers.

\section{Risk of Bias in Individual Studies}

Three reviewers evaluated the quality of entailed trials based on the PEDro (Physiotherapy Evidence Database) scale scored using 10 items with the first item (external 
validity of the article) quality assessments of controlled interventional studies tool. ${ }^{26,27}$ The PEDro scale surveys the methodological quality of trials based on critical criteria, such as concealed assignment, intention-to-treat examination, and ampleness of follow-up. These characteristics make the PEDro scale a valuable apparatus to evaluate the methodological quality of RCTs. This review considered trials with a score of 5 to 7 as moderate quality, and a score of $\geq 8$ as a high-quality study (Table 1 ).

\section{Data Extraction}

Information extraction was done based on the data retrieval template of the Cochrane Consumer and Communication Review Group. Two reviewers (A.A. and K.G.) extracted the data independently and the third author (H.M.) checked the extracted data. Disagreements were settled by discourse with the third author. The following data were extracted from each RCT: author name and year of publication, stroke definition (stroke severity measure, type, and duration), number of participants in treatment and control groups, types of treatment both in experimental and control groups, mean follow-up time, mean age of the participants, and treatment outcomes (baseline, follow-up, and end of treatment). The effectiveness of interventions for each result, mean and standard deviation of result measures at pattern, after treatment, and at mid-follow-up, was extracted and synthesized for comparison.

\section{Results}

\section{Study Selection}

A total of 810 articles were recognized by the searching strategy. After adjusting for duplicates, 748 remained. After title and abstract screening of studies, 348 studies were expelled. After full content screening out of 52 articles, nine randomized controlled trials were included in this review (Figure 1).

\section{Study Characteristics}

The detailed descriptions of characteristics and results of the outcomes for the included trials are presented in Table 2. A total of nine trials with 332 participants were synthesized. All nine trials evaluated the efficacy of body awareness therapy on balance and gait function. The synthesized characteristics and outline of the results about the included trials based on the PICO standard are described below.

\section{Participants}

The large part of included trials selected from recovery center conceded members living with a stroke. The mean age of the members considered extended from 48.9 (10.5) to $65.6(9.2)$ years. ${ }^{28,29}$ The mean time since stroke determination extended from 3.6 to 50.7 months. ${ }^{30,31}$ The majority of included trials enlisted more members with ischemic sort of injury.

Table I Quality Assessment of Included RCTs

\begin{tabular}{|c|c|c|c|c|c|c|c|c|c|}
\hline PEDro Items & $\begin{array}{l}\text { Liu } \\
\text { et al, } \\
2016^{28}\end{array}$ & $\begin{array}{l}\text { Lindvall and } \\
\text { Forsberg, } \\
2014^{29}\end{array}$ & $\begin{array}{l}\text { Oostra } \\
\text { et al, } \\
2015^{30}\end{array}$ & $\begin{array}{l}\text { Kim } \\
\text { et al, } \\
2015^{31}\end{array}$ & $\begin{array}{l}\text { Bang } \\
\text { and Cho, } \\
2017^{32}\end{array}$ & $\begin{array}{l}\text { Bang } \\
\text { and Cho, } \\
2015^{34}\end{array}$ & $\begin{array}{l}\text { Farqalit and } \\
\text { Shahnawaz, } \\
2013^{33}\end{array}$ & $\begin{array}{l}\text { Kutlay } \\
\text { et al, } \\
2018^{35}\end{array}$ & $\begin{array}{l}\text { Cho } \\
\text { et al, } \\
2013^{36}\end{array}$ \\
\hline Eligibility & Yes & Yes & Yes & Yes & No & Yes & No & Yes & Yes \\
\hline Random allocation & Yes & Yes & Yes & Yes & Yes & Yes & Yes & Yes & Yes \\
\hline Concealed allocation & Yes & Yes & No & Yes & Yes & Yes & No & Yes & No \\
\hline Baseline comparability & Yes & No & Yes & Yes & Yes & Yes & Yes & Yes & Yes \\
\hline Blind participants & No & No & Yes & Yes & No & No & No & Yes & Yes \\
\hline Blind therapists & No & No & No & No & No & No & Yes & Yes & Yes \\
\hline Adequate follow-up & No & No & Yes & No & Yes & Yes & Yes & No & No \\
\hline Blind assessors & Yes & No & No & Yes & Yes & No & Yes & Yes & Yes \\
\hline $\begin{array}{l}\text { Intention to treat } \\
\text { analysis }\end{array}$ & No & Yes & Yes & Yes & No & No & No & Yes & Yes \\
\hline $\begin{array}{l}\text { Between-group } \\
\text { comparisons }\end{array}$ & Yes & Yes & Yes & Yes & Yes & Yes & Yes & Yes & Yes \\
\hline $\begin{array}{l}\text { Point estimates and } \\
\text { variability }\end{array}$ & Yes & Yes & Yes & Yes & Yes & Yes & Yes & Yes & Yes \\
\hline Total score & $6 / 10$ & $7 / 10$ & $5 / 10$ & $8 / 10$ & $6 / 10$ & $6 / 10$ & $7 / 10$ & $9 / 10$ & $8 / 10$ \\
\hline Quality & Moderate & Moderate & Moderate & High & Moderate & Moderate & Moderate & High & High \\
\hline
\end{tabular}




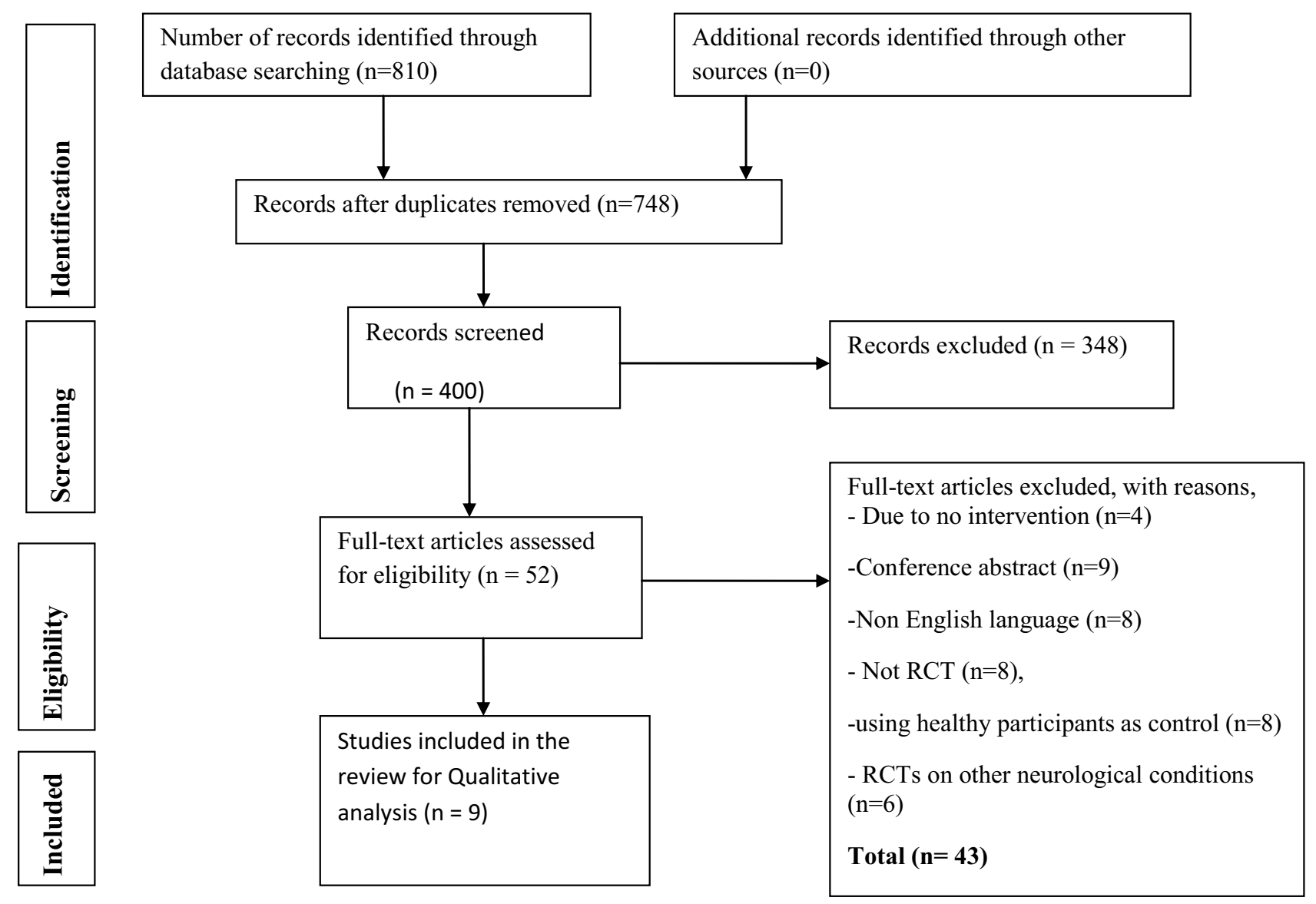

Figure I Preferred Reporting Items for Systematic Reviews and Meta-Analyses (PRISMA) diagram.

\section{Interventions}

Studies comparing the effectiveness of BAT and comparison/control group for treadmill training, gait training, walking training, usual daily activities, and conventional stroke rehabilitation were included. The intervention training varied from 20 to 60 minutes per session, 3 to 5 times per week for a 3 to 8 week period. ${ }^{29,32}$

\section{Outcome Measures}

Data were extracted for the following outcomes: balance, gait, walking speed, and functional status. The primary outcome measures of this review were the 10Meter Walk Test (10MWT) and Berg Balance Scale (BBS). Five trials utilized Berg's Balance Scale for balance assessment. ${ }^{28,29,32-34}$ Only two trials used the Timed Up and Go Test for dynamic balance ability. ${ }^{31,34}$ The baseline balance performance of the participants varied from 33.9 (6.2) to 48.8 (4.6), and 29.3 (8.6) to 46.5 (7) for the experimental and control group respectively. ${ }^{29,33}$ After follow-up, the balance score of the participants ranged from 46.7 to 52.2
(4.6), ${ }^{28,29}$ and $42.6(7.3)$ to $47.8(7.3)^{29,33}$ for the experimental and control group respectively.

Three trials ${ }^{30,31,34}$ utilized the 10-Meter Walk Test to determine the degree ambulatory/walking speed and two trials $^{29,33}$ used the Timed Up and Go Test for mobility/gait assessment. The pattern ambulatory speed of the members extended from 0.44 to $33.4 \mathrm{~m} / \mathrm{s}$ and 0.53 to $29 \mathrm{~m} / \mathrm{s}$ for the experimental and control group respectively. ${ }^{30,34}$ After follow-up, ambulatory speed of the subjects was extended from 0.55 to $19.3 \mathrm{~m} / \mathrm{s}(3,22)$ and 0.53 to $23.96 \mathrm{~m} / \mathrm{s}^{31,34}$ for the experimental and control group respectively. Only one trial used FIM to assess the functional status of the participants. $^{35}$

\section{Risk of Bias Within Studies}

The chance of predisposition inside individual trials and the conclusion of all items for the enlisted studies are presented in Table 1. Out of the encompassed studies, the PEDro score extended from 5 to $9^{27}$ with a mean score of 7. All members were randomly allocated and all studies gave satisfactory results and analysis. As it was, 
three trials fizzled to concealed allotment, ${ }^{30,33,36}$ and one trial did not evaluate baseline comparability. ${ }^{29}$ Only three trials blinded therapists ${ }^{33,35,36}$ and four trials blinded their members. ${ }^{30,31,35,36}$ The lower scoring trials were basically checked down on blinding of members, deliberate/intention to treat analysis, and blinding the therapist. With all things, the most prominent potential source of inclination was related to blinding.

\section{Effects of BAT on Balance}

Detailed information on balance outcome extracted from the articles has been summarized and presented in Table 2. Eight studies, with 288 individuals, supplied the published treatment effect on balance..$^{20,28,29,31,33-36}$ Out of eight trials, seven of them $(n=242)$ mentioned that balance ability of stroke patients was significantly improved in BAT groups as compared to the control groups in all outcome measures (BBS, TUG). ${ }^{20,28,31,33-36}$ However, only one study $(n=46)$ reported that body awareness therapy had no significant improvement in balance ability compared to that of the control groups. ${ }^{29}$ In the experimental intervention group, considerable improvement was located for the Berg Balance Scale tests.

\section{Effects of BAT on Gait Function}

All the included trials, nine studies with 332 individuals, furnished the post-remedy effect on gait. Out of the included trials, seven of them $(n=274)$ pronounced that BAT had a beneficial effect on gait function compared with the control groups. ${ }^{30-33,35-37}$ Despite this, two studies $(n=58)$ showed that significant enhancement was no longer found on gait for BAT/experimental groups as compared to control groups. ${ }^{29,34}$

\section{Discussion}

The primary intention of this systematic review was to synthesize the effectiveness of body awareness therapy on balance and gait function in stroke survivors. To this point, there had been no reviews that determine the effectiveness of body awareness therapy on stability and gait function in stroke sufferers in a systematic way. To the best of our understanding, this is the primary systematic evaluation to investigate the current evidence about the effectiveness of body awareness therapy on balance and gait function in individuals with stroke.

The majority of the included trials with mild to excessive great evidence suggested that BAT became powerful on balance and gait function for stroke survivors. The general effects of BAT on stroke survivors were turned into evaluation for a distinct period of intervention. The effect of BAT on balance was evaluated in eight studies. Seven studies pronounced that using BAT caused improved balance capacity in patients with stroke. However, in one study, BAT was not effective for balance improvement. ${ }^{29}$ Besides, two studies ${ }^{30,35}$ reported the effect of BAT on unilateral forget and functional outcome that showed significant improvement in stroke survivors with unilateral forget and functioning. However, Braun et al indicated that no differences were found between groups of BAT/intellectual practice with conventional therapy, compared to conventional therapy alone. The possible differences might be that the authors' suggested that this treatment for elderly stroke patients might be difficult due to the complexity of the intervention. $^{38}$

The effect of BAT on gait was also evaluated in all included studies. Seven of them reported that BAT had a beneficial effect on gait function as compared to the control groups. In contradiction to this, two studies showed that a significant improvement of gait function was not found for stroke patients who received BAT compared to control groups. ${ }^{29,34}$ For instance, the study done by Lindvall and Forsberg showed that no effects have been seen on stability, mobility balance self-belief, and subjective fitness repute after 8 weeks of body awareness therapy as compared to no intervention. ${ }^{29}$ The possible explanation could be that the training session was only once a week for the 8-week duration, bodily activity levels have not been measured in either group, and some of the individuals allocated to the control groups have commenced exercise on their own. Nevertheless, in the experimental intervention group, widespread variations were located between the baseline check and the comply with uptake for the Berg Balance Scale, and the mean exchange within the intervention group was 3.6 factors. On the contrary, the study done by Bang et $\mathrm{al}^{39}$ reported that body awareness training showed a positive effect on balance in patients with chronic stroke in the Berg Balance Scale and Timed Up and Go Test compared with the control groups. This might be that balance ability improved due to BAT consisting of sensory stimulation and awareness of shifting body weight that helps to maintain their balance. Also, the study conducted by Liu M, et al $(2016)^{28}$ pronounced that body awareness therapy showed a positive impact on balance in sufferers with chronic stroke on the Berg balance Scale and Timed Up and Go Test compared with the control groups. This might be that the authors suggested 
Table 2 Summary of Included Randomized Controlled Trials

\begin{tabular}{|c|c|c|c|c|}
\hline $\begin{array}{l}\text { Authors } \\
\text { (Years) }\end{array}$ & $\begin{array}{l}\text { Participant } \\
\text { Characteristics }\end{array}$ & Interventions & $\begin{array}{l}\text { Outcome } \\
\text { Measures }\end{array}$ & Results \\
\hline $\begin{array}{l}\text { Lindvall and } \\
\text { Forsberg, } \\
2014^{29}\end{array}$ & $\begin{array}{l}46 \text { total participants: EG } \\
(n=22), C G(n=22) \\
\text { Mean age (years): EG; } 62.1 \\
\text { (I I.4), CG; } 65.6(9.2) \\
\text { Duration (years): EG; } 4.1 \\
\text { (3.8), CG; } 4.2 \text { (4.5) }\end{array}$ & $\begin{array}{l}E G=\text { body awareness therapy } 60 \\
\text { minutes once a week for } 8 \text { weeks plus } \\
\text { usual daily activities. } \\
\text { CG=usual daily activities }\end{array}$ & $\begin{array}{l}-\mathrm{BBS} \\
-\mathrm{TUG} \\
-6 \mathrm{MWT} \\
-\mathrm{ABCS}\end{array}$ & $\begin{array}{l}\text {-Significant improvement was not } \\
\text { found on balance and gait for the } \\
\text { experimental group compared to the } \\
\text { control group }\end{array}$ \\
\hline $\begin{array}{l}\text { Bang and } \\
\text { Cho, } \\
2015^{34}\end{array}$ & $\begin{array}{l}\text { I } 2 \text { participants: } E G(n=6), C G \\
(n=6) \\
\text { Mean age; EG; } 63.7 \pm 7.1, C G ; \\
64.6 \pm 5.9 \\
\text { Duration (weeks) EG; } 23.5 \\
\pm 5.6, \text { CG; } 21.8 \pm 7.3\end{array}$ & $\begin{array}{l}\text { EG=BAT for } 20 \text { minutes and walking } \\
\text { training for } 30 \text { minutes a day, } 5 \text { times } \\
\text { a week for } 4 \text { weeks. } \\
\text { CG=walking training for } 30 \text { minutes/ } \\
\text { day, } 5 \text { times per week for } 4 \text { weeks }\end{array}$ & $\begin{array}{l}\text {-BBS } \\
\text {-TUG } \\
\text { - IOMWT }\end{array}$ & $\begin{array}{l}\text {-Body awareness training group } \\
\text { showed more significant } \\
\text { improvements in the BBS and TUG } \\
\text { than the control group } \\
\text {-But, there was no significant } \\
\text { difference in the 10-Meter Walk Test } \\
\text { between the groups }\end{array}$ \\
\hline $\begin{array}{l}\text { Kutlay et al, } \\
2018^{35}\end{array}$ & $\begin{array}{l}64 \text { stroke patients: EG } \\
(n=25), C G(n=28) \\
\text { Mean age (years): EG, } 62 \\
(54.5-67) ; C G, 63(54-70.75) \\
\text { Duration (months): EG, } 4 \\
(2-10.5) ; C G, 3(2-4.75)\end{array}$ & $\begin{array}{l}\text { EG=KAT } 20-30 \text { minutes for } 5 \text { days per } \\
\text { week for } 4 \text { weeks, plus a conventional } \\
\text { rehabilitation programme for } 5 \text { days } \\
\text { a week, } 2-3 \text { h/day for } 4 \text { weeks. } \\
\text { CG=conventional, stroke } \\
\text { rehabilitation programme } 5 \text { days } \\
\text { a week, } 2-3 \text { h/day for } 4 \text { weeks }\end{array}$ & $\begin{array}{l}-\mathrm{BIT} \\
\text {-FIM }\end{array}$ & $\begin{array}{l}\text {-Kinaestheticability training provides } \\
\text { clinically meaningful improvement in } \\
\text { stroke patients } \\
\text { with unilateral neglect }\end{array}$ \\
\hline $\begin{array}{l}\text { Kim et al, } \\
2015^{31}\end{array}$ & $\begin{array}{l}30 \text { patients with stroke: GI } \\
(n=10), G 2(n=10), G 3 \\
(n=10) \\
\text { Mean age (years): EG; } 59.40 \\
\text { (8.63), CG; } 56.40 \text { (II.87) } \\
\text { Duration (months): EG; } 37.80 \\
\text { (22.40), CG; } 50.70 \text { (I3.83) }\end{array}$ & $\begin{array}{l}\text { EGI=general physical therapy plus } \\
\text { pressure sense perception training on } \\
\text { a stable surface } 30 \text { minutes/session, } 3 \\
\text { days per week for } 4 \text { weeks. } \\
\text { EG2=general physical therapy and the } \\
\text { pressure sense perception training on } \\
\text { an unstable surface } 30 \text { minutes/ } \\
\text { session, } 3 \text { days per week for } 4 \text { weeks. } \\
\text { CG } 3=\text { general physical therapy alone }\end{array}$ & $\begin{array}{l}\text {-FRT } \\
\text {-TUG } \\
\text {-IOMWT }\end{array}$ & $\begin{array}{l}\text {-Experimental groups showed } \\
\text { significant differences in PE, FRT, TUG, } \\
\text { and IOMWT compared to the control } \\
\text { group ( } p<0.05) \\
\text {-Group } 2 \text { (pressure sense perception } \\
\text { training on an unstable surface) was } \\
\text { significantly different in } \\
\text { PE, FRT, and IOMWT from group I } \\
(p<0.05)\end{array}$ \\
\hline $\begin{array}{l}\text { Oostra } \\
\text { et al, } \\
2015^{30}\end{array}$ & $\begin{array}{l}44 \text { participants with stroke: } \\
\text { EG (n=2I), CG ( } n=23) \text { Mean } \\
\text { age: EG; } 50.3 \text { (I2.8) CG; } 53.7 \\
\text { (I2.0) } \\
\text { Duration (months): EG; } 4.7 \\
\text { (3.I), CG; } 3.6(2.0)\end{array}$ & $\begin{array}{l}\text { EG=received MIT } 30 \text { minutes dailyFor } \\
6 \text { weeks. } \\
\text { CG=received a muscle relaxation } \\
\text { (physically tense) in particular muscle } \\
\text { groups } 30 \text { minutes daily for } 6 \text { weeks. } \\
\text { Both groups received a standard } \\
\text { rehabilitation consisting of } 2 \text { h physical } \\
\text { (Bobath Concept) therapy and I } \\
\text { h occupational therapy daily }\end{array}$ & $\begin{array}{l}\text {-Mental } \\
\text { chronometry } \\
\text { test } \\
\text {-IOMWT } \\
\text {-FMA-LE }\end{array}$ & $\begin{array}{l}\text { Significant between-group differences } \\
\text { were found, with the vividness of } \\
\text { kinesthetic imagery and the walking } \\
\text { test results improving more in the } \\
\text { motor imagery group than in the } \\
\text { muscle relaxation group }\end{array}$ \\
\hline $\begin{array}{l}\text { Liu et al, } \\
2016^{28}\end{array}$ & $\begin{array}{l}\text { A total of } 50 \text { patients with } \\
\text { stroke: } E G(n=25), C G \\
(n=25) \\
\text { Mean age (years): EG; } 48.9 \\
\text { (I0.5), CG; } 51.7 \text { (I2.4) } \\
\text { Duration (months): EG; } 3.7 \\
\text { (I.I), CG; } 4.1 \text { (I.4) }\end{array}$ & $\begin{array}{l}E G=\text { given the modified sit-to-stand } \\
\text { training in which the paretic foot is } \\
\text { placed posterior } 30 \text { minutes, five times } \\
\text { a week, for } 4 \text { weeks. Both groups } \\
\text { received CPT. } \\
\text { CG=received the sit-to-stand training } \\
\text { with symmetrical foot position } 30 \\
\text { minutes, five } \\
\text { times a week, for } 4 \text { weeks }\end{array}$ & $\begin{array}{l}\text {-BBS } \\
\text {-CoP sway } \\
\text { length }\end{array}$ & $\begin{array}{l}\text { A modified sit-to-stand training } \\
\text { improves the balance function, weight- } \\
\text { bearing asymmetry, and centre of } \\
\text { pressure sway in hemiplegic stroke } \\
\text { patients compared to the control } \\
\text { group }\end{array}$ \\
\hline
\end{tabular}

(Continued) 
Table 2 (Continued).

\begin{tabular}{|c|c|c|c|c|}
\hline $\begin{array}{l}\text { Authors } \\
\text { (Years) }\end{array}$ & $\begin{array}{l}\text { Participant } \\
\text { Characteristics }\end{array}$ & Interventions & $\begin{array}{l}\text { Outcome } \\
\text { Measures }\end{array}$ & Results \\
\hline $\begin{array}{l}\text { Farqalit and } \\
\text { Shahnawaz, } \\
2013^{33}\end{array}$ & $\begin{array}{l}40 \text { patients ( } 29 \text { men, II } \\
\text { women) EG ( } n=20), \text { CG } \\
\text { ( } n=20) \\
\text { Age range (years): } 40-60 \text { in } \\
\text { both groups } \\
\text { Duration (years): I-5 }\end{array}$ & $\begin{array}{l}\text { EG=underwent STS training with the } \\
\text { asymmetrical foot position, } 10 \text { sets of } \\
10 \text { repetitions each for } 5 \text { days a week } \\
\text { for the duration of } 4 \text { weeks. } \\
\text { CG=performed STS training with } \\
\text { symmetrical foot position, } 10 \text { sets of } \\
10 \text { repetitions each for } 5 \text { days a week } \\
\text { for the duration of } 4 \text { weeks. Both } \\
\text { training groups also received } \\
\text { a stretching, strengthening exercise } \\
\text { program }\end{array}$ & $\begin{array}{l}\text {-BBS } \\
\text {-STS } \\
\text { performance - } \\
\text { TUG }\end{array}$ & $\begin{array}{l}\text {-Asymmetrical foot position during } \\
\text { STS training resulted } \\
\text { in improved balance and upright } \\
\text { mobility in patients with chronic } \\
\text { stroke as compared to the } \\
\text { symmetrical foot position }\end{array}$ \\
\hline $\begin{array}{l}\text { Bang and } \\
\text { Cho, } \\
2017^{32}\end{array}$ & $\begin{array}{l}\text { I8 chronic stroke patients: } \\
\text { EG ( } n=9) \text { and CG }(n=9) \\
\text { Mean age (years): EG; 6I.53 } \\
\text { (7.I8), CG; 59.9I (5.35) } \\
\text { Duration (months): EG; } 8.49 \\
(2.17), \text { CG; } 7.95 \text { (I.85) }\end{array}$ & $\begin{array}{l}E G=\text { received a postural control } \\
\text { training for } 30 \text { minutes, five times per } \\
\text { week for } 3 \text { weeks and } 60 \text { minutes of } \\
\text { comprehensive rehabilitation } \\
\text { treatment. } \\
C G=\text { performed a treadmill training for } \\
30 \text { minutes five times per week for } 3 \\
\text { weeks and } 60 \text { minutes of } \\
\text { comprehensive rehabilitation } \\
\text { treatment }\end{array}$ & $\begin{array}{l}\text {-BBS } \\
\text {-GAITRite } \\
\text { system }\end{array}$ & $\begin{array}{l}\text {-Experimental group exhibited greater } \\
\text { improvement in the gait and balance } \\
(p=0.01 ; 95 \% \mathrm{Cl} \text { I.04-6.74) compared } \\
\text { to the control group }\end{array}$ \\
\hline $\begin{array}{l}\text { Cho et al, } \\
2013^{36}\end{array}$ & $\begin{array}{l}28 \text { stroke patients: } E G(n=\mid 5) \text {, } \\
C G(n=\mid 3) \\
\text { Mean age (years): EG; } 53.93 \\
(\mid 2.60), C G ; 53.85(\mid 2.44) \\
\text { Durations (months): EG; } \\
44.67 \text { (I9.19), CG; } 45.54 \\
(16.7 I)\end{array}$ & $\begin{array}{l}E G=\text { received motor imagery training } \\
\text { with gait training } 45 \text { minutes/day, } 3 \\
\text { times/week for } 6 \text { weeks. } \\
C G=\text { received only gait training } 30 \\
\text { minutes/day, } 3 \text { times/week for } 6 \text { weeks }\end{array}$ & $\begin{array}{l}\text {-FRT } \\
\text {-TUG } \\
\text {-IOMWT } \\
\text {-FMA-LE }\end{array}$ & $\begin{array}{l}\text {-Motor imagery training with gait } \\
\text { training was more effective than gait } \\
\text { training alone in enhancing the balance } \\
\text { and gait abilities }\end{array}$ \\
\hline
\end{tabular}

Abbreviations: EG, experimental group; CG, control group; ABCS, Activities-specific Balance Confidence Scale; BBS, Berg Balance Scale; TUG, Timed Up and Go Test; IOMWT, I0-Meter Walk Test; BIT, Behavioral Inattention Test; FIM, Functional Independence Measure; FRT, Functional Reach Test; KAT, kinaesthetic ability training; MIT, motor imagery training; MR, muscle relaxation; FMA-LE, Fugl-Meyer assessment - lower extremity.

stability capability progressed due to BAT comprising sensory stimulation and cognizance of shifting body weight that facilitates to keep their stability. But, there was no sizable difference in the 10-Meter Walk Test between the groups. Therefore, taking walks pace no longer displayed vast variations among groups. This can be due to walking speed being associated more to energy than to sensation, and there was no follow-up as much as degree of the lengthy-term effect.

A study done by Kutlay et al shows mental practice training provides improvement in functions and unilateral neglect problems in stroke survivors. Consequently, it may be beneficial as an adjunctive therapy for rehabilitation in stroke sufferers. $^{35}$ Likewise, the study conducted by Oostra et al confirmed that kinesthetic imagery and the walking test effects improve greater in the motor imagery group than in the muscle relaxation group. ${ }^{30}$

A study done by Kim et al showed that pressure sence perception training (PSPT) on a risky surface might be a significantly greater effective approach for improving somatosensory characteristics, stability, and taking walks ability, than PSPT on a stable surface. ${ }^{31}$ The viable reason for the development in motor performance such as stability and taking walks capability may additionally be inferred from the following; PSPT via the conscious control level is clinched through the cortex and pyramidal. Similarly, Liu et al's study revealed that modified sit-to-stand education improves the stability characteristics, weight-bearing asymmetry, and center of pressure sway in hemiplegic stroke patients compared to the control group. ${ }^{28}$ 
Moreover, Farqalit and Shahnawaz evidenced that asymmetrical foot function in the course of sit down to stand training resulted in advanced balance and upright mobility in patients with continual stroke compared to the symmetrical foot function. ${ }^{33}$ Further, the study done by Bang and Cho suggested that postural manipulate training enhances stability and walking capacity of participants with chronic stroke. $^{32}$

In the study done by Cho et $\mathrm{al}^{36}$ motor imagery schooling combined with gait became more effective than gait training in improving the stability and gait function of continual stroke sufferers. This is probably because motor imagery training may additionally grow stability capability by way of stimulating proprioception and reducing their dependence on visual function for improving stability. In this study, gait speed elevated more within the experimental group than inside the control group (28\% vs $18 \%$, respectively). Similarly, Dickstein et al confirmed that the walking pace of stroke survivors increased by way of $23 \%$ after 6 weeks of imagery training. ${ }^{40}$ In the study by Hwang et al, the gait speed of unilateral body weakness individuals increased via $15 \%$ after 4 weeks of imagery training. ${ }^{41}$ Motor imagery training may also consequently have the effect of enhancing gait capacity. But, Liu et al no longer revealed any beneficial results on enhancing the motor feature of the lower limbs. ${ }^{42}$ For this reason, the likely variations between the research findings are probably associated with the protocols used for motor imagery schooling. Imagery schooling/training associated with motion that entails extremities may consequently be used to enhance motor characteristics in stroke sufferers.

In two studies comparing motor imagery training (MIT) and conventional physiotherapy (CPT) groups of participants on sub-acute stroke, the finding of these studies showed significant improvements in stroke survivors with unilateral neglect and gait function. ${ }^{30,35}$ With regards to subjects with chronic stroke, four trials comparing BAT and CPT groups confirmed significant improvement in balance and gait function. ${ }^{28,32,33,36}$

Taken together, the effects of two studies might suggest that BAT had no beneficial effect on balance and gait. However, based on the findings of seven similar studies, a more plausible explanation confirmed that BAT had a significant improvement in balance and gait function in stroke survivors in comparison to the control groups.

\section{Limitations}

This study had subsequent limitations: this review included only English language articles. Hence, there is probably a hazard of lacking articles posted in non-English languages. The heterogeneity across the research for the entire said consequences in the intervention and beyond the intervention durations should be changed into not estimated by means of pooled evaluation. Including studies with a short treatment duration should occur in the view that a longer remedy may probably result in a massive intergroup difference.

\section{Clinical Implication}

This review suggested that body awareness therapy seems to result in stepped forward results on balance and gait function. Medical choice making will be relying on the cognitional repute of subjects, particularly in elder age stroke survivors.

\section{Conclusion}

Body awareness therapy was found to improve balance and gait function of subjects with stroke. Even though this review found that BAT is powerful in enhancing balance and gait compared to different intervention, amazing interest is needed while we use BAT for stroke subjects as the path of disorder length. Future studies will even want to settle the equivocal facts on whether or not patients' satisfactory lifestyles are notably advanced with the sooner initiation of BAT for patients with stroke at an acute stage.

\section{Ethical Approval}

Ethical approval or affected person consent was no longer required because the prevailing look became an overview of preceding published literature.

\section{Disclosure}

The authors report no conflicts of interest in this work.

\section{References}

1. Greshman G, Duncan P, Staston W, Post-stroke rehabilitation guideline panel. Post-stroke rehabilitation. Clinical Practice Guideline No. 16 CAHCPR Publication No. 95-0662). Rockville, MD: US Department of Health and Human Services, Public Health Service, Agency for Health Care Policy and Research; May 1995.

2. O'Sullivan SB, Schmitz TJ, Fulk G. Physical Rehabilitation. FA Davis; 2019.

3. Rousseaux M, Allart E, Bernati T, et al. Anatomical and psychometric relationships of behavioral neglect in daily living. Neuropsychologia. 2015;70:64-70. doi:10.1016/j.neuropsychologia.2015.02.011 
4. Edmans J, Lincoln N. The frequency of perceptual deficits after stroke. $B r \quad J$ Occup Ther. 1989;52(7):266-270. doi:10.1177/ 030802268905200706

5. Bosma MS, Nijboer TC, Caljouw MA, et al. Impact of visuospatial neglect post-stroke on daily activities, participation and informal caregiver burden: a systematic review. Ann Phys Rehabil Med. 2019.

6. Bieńkiewicz MM, Brandi M-L, Hughes C, et al. The complexity of the relationship between neuropsychological deficits and impairment in everyday tasks after stroke. Brain Behav. 2015;5(10):e00371. doi: $10.1002 /$ brb3.371

7. van Stralen HE, Dijkerman HC, Biesbroek JM, et al. Body representation disorders predict left right orientation impairments after stroke: a voxel-based lesion symptom mapping study. Cortex. 2018;104:140-153. doi:10.1016/j.cortex.2017.05.025

8. Hyndman D, Ashburn A. People with stroke living in the community: attention deficits, balance, ADL ability and falls. Disabil Rehabil. 2003;25(15):817-822. doi:10.1080/0963828031000122221

9. Stapleton T, Ashburn A, Stack E. A pilot study of attention deficits, balance control and falls in the subacute stage following stroke. Clin Rehabil. 2001;15(4):437-444. doi:10.1191/026921501678310243

10. Hyndman D, Ashburn A, Yardley L, et al. Interference between balance, gait and cognitive task performance among people with stroke living in the community. Disabil Rehabil. 2006;28(13-14):849-856. doi:10.1080/09638280500534994

11. Michael KM, Allen JK, Macko RF. Reduced ambulatory activity after stroke: the role of balance, gait, and cardiovascular fitness. Arch Phys Med Rehabil. 2005;86(8):1552-1556. doi:10.1016/j. apmr.2004.12.026

12. Bang D-H, Shin W-S, Kim S-Y, et al. The effects of action observational training on walking ability in chronic stroke patients: a double-blind randomized controlled trial. Clin Rehabil. 2013;27 (12):1118-1125. doi:10.1177/0269215513501528

13. Richards CL, Malouin F, Wood-Dauphinee S, et al. Task-specific physical therapy for optimization of gait recovery in acute stroke patients. Arch Phys Med Rehabil. 1993;74(6):612-620. doi:10.1016/ 0003-9993(93)90159-8

14. Choi J-U, Kang S-H. The effects of patient-centered task-oriented training on balance activities of daily living and self-efficacy following stroke. J Phys Ther Sci. 2015;27(9):2985-2988. doi:10.1589/ jpts. 27.2985

15. Gyllensten AL, Hansson L, Ekdahl C. Patient experiences of basic body awareness therapy and the relationship with the physiotherapist J Bodyw Mov Ther. 2003;7(3):173-183. doi:10.1016/S1360-8592(02) 00068-2

16. Catalan-Matamoros D, Helvik-Skjaerven L, Labajos-Manzanares MT, et al. A pilot study on the effect of basic body awareness therapy in patients with eating disorders: a randomized controlled trial. Clin Rehabil. 2011;25(7):617-626. doi:10.1177/0269215510394223

17. Roxendal G. Body Awareness Therapy and the Body Awareness Scale: Treatment and Evaluation in Psychiatric Physiotherapy [doctoral dissertation]. Göteborg, Sweden: University of Göteborg; 1985.

18. Cheng P-T, Wu S-H, Liaw M-Y, et al. Symmetrical body-weight distribution training in stroke patients and its effect on fall prevention. Arch Phys Med Rehabil. 2001;82(12):1650-1654. doi:10.1053/apmr.2001.26256

19. Eriksson E, Möller IE, Söderberg RH, et al. Body awareness therapy: a new strategy for relief of symptoms in irritable bowel syndrome patients. World J Gastroenterol. 2007;13(23):3206. doi:10.3748/wjg. v13.i23.3206

20. Kong HN, Bang DH, Shin WS. Effects of balance training on different support surface on balance and gait in patients with chronic stroke. Cho. 2015;10(3):275-283.

21. Hedlund L, Gyllensten AL. The experiences of basic body awareness therapy in patients with schizophrenia. J Bodyw Mov Ther. 2010;14 (3):245-254. doi:10.1016/j.jbmt.2009.03.002
22. Moher D, Shamseer L, Clarke M, et al. Preferred reporting items for systematic review and meta-analysis protocols (PRISMA-P) 2015 statement. Syst Rev. 2015;4(1):1. doi:10.1186/2046-4053-4-1

23. Richardson WS, Wilson MC, Nishikawa J, et al. The well-built clinical question: a key to evidence-based decisions. ACP J Club. 1995;123(3):A12-3.

24. Villanueva EV, Burrows EA, Fennessy PA, et al. Improving question formulation for use in evidence appraisal in a tertiary care setting: a randomised controlled trial [ISRCTN66375463]. BMC Med Inform Decis Mak. 2001;1(1):4. doi:10.1186/1472-6947-1-4

25. Snowball R. Using the clinical question to teach search strategy: fostering transferable conceptual skills in user education by active learning. Health Libr Rev. 1997;14(3):167-172. doi:10.1046/j.13652532.1997.1430133.x-i1

26. de Morton NA. The PEDro scale is a valid measure of the methodological quality of clinical trials: a demographic study. Aust $J$ Physiother. 2009;55(2):129-133. doi:10.1016/S0004-9514(09)70 043-1

27. Maher CG, Sherrington C, Herbert RD, et al. Reliability of the PEDro scale for rating quality of randomized controlled trials. Phys Ther. 2003;83(8):713-721. doi:10.1093/ptj/83.8.713

28. Liu M, Chen J, Fan W, et al. Effects of modified sit-to-stand training on balance control in hemiplegic stroke patients: a randomized controlled trial. Clin Rehabil. 2016;30(7):627-636. doi:10.1177/ 0269215515600505

29. Lindvall MA, Forsberg A. Body awareness therapy in persons with stroke: a pilot randomized controlled trial. Clin Rehabil. 2014;28 (12):1180-1188. doi:10.1177/0269215514527994

30. Oostra KM, Oomen A, Vanderstraeten G, et al. Influence of motor imagery training on gait rehabilitation in sub-acute stroke: a randomized controlled trial. J Rehabil Med. 2015;47(3):204-209. doi:10.2340/16501977-1908

31. Kim BS, Bang DH, Shin WS. Effects of pressure sense perception training on unstable surface on somatosensory, balance and gait function in patients with stroke. Cho. 2015;10(3):237-245.

32. Bang D-H, Cho H-S. The effect of postural control training on balance and walking ability in patients with chronic stroke. Korean Soc Phys Me. 2017;12(2):59-66. doi:10.13066/kspm.2017.12.2.59

33. Farqalit R, Shahnawaz A. Effect of foot position during sit-to-stand training on balance and upright mobility in patients with chronic stroke. Hong Kong Physiother J. 2013;31(2):75-80. doi:10.1016/j. hkpj.2013.06.001

34. Bang D-H, Cho H-S. Effect of body awareness training on balance and walking ability in chronic stroke patients: a randomized controlled trial. J Phys Ther Sci. 2016;28(1):198-201. doi:10.1589/ jpts. 2016.198

35. Kutlay S, Genç A, Gök H, et al. Kinaesthetic ability training improves unilateral neglect and functional outcome in patients with stroke: a randomized control trial. J Rehabil Med. 2018;50 (2):159-164. doi:10.2340/16501977-2301

36. Cho H-Y, Kim J-S, Lee G-C. Effects of motor imagery training on balance and gait abilities in post-stroke patients: a randomized controlled trial. Clin Rehabil. 2013;27(8):675-680. doi:10.1177/ 0269215512464702

37. Chung E-J, Kim J-H, Lee B-H. The effects of core stabilization exercise on dynamic balance and gait function in stroke patients. J Phys Ther Sci. 2013;25(7):803-806. doi:10.1589/jpts.25.803

38. Braun SM, Beurskens AJ, Kleynen M, et al. A multicenter randomized controlled trial to compare subacute 'treatment as usual'with and without mental practice among persons with stroke in Dutch nursing homes. J Am Med Dir Assoc. 2012;13(1):85. e1-85. e7. doi:10.1016/j.jamda.2010.07.009

39. Bang D-H, Noh H-J, Cho H-S. Effects of body awareness training on mild visuospatial neglect in patients with acute stroke: a pilot randomized controlled trial. J Phys Ther Sci. 2015;27(4):1191-1193. doi:10.1589/jpts.27.1191 
40. Dickstein R, Dunsky A, Marcovitz E. Motor imagery for gait rehabilitation in post-stroke hemiparesis. Phys Ther. 2004;84 (12):1167-1177. doi:10.1093/ptj/84.12.1167

41. Hwang S, Jeon $\mathrm{HS}$, Yi $\mathrm{CH}$, et al. Locomotor imagery training improves gait performance in people with chronic hemiparetic stroke: a controlled clinical trial. Clin Rehabil. 2010;24(6):514-522. doi:10.1177/0269215509360640
42. Liu KP, Chan CC, Lee TM, et al. Mental imagery for promoting relearning for people after stroke: a randomized controlled trial. Arch Phys Med Rehabil. 2004;85(9):1403-1408. doi:10.1016/j.apmr.2003.12.035

\section{Publish your work in this journal}

The Open Access Journal of Clinical Trials is an international, peerreviewed, open access journal publishing original research, reports, editorials, reviews and commentaries on all aspects of clinical trial design, management, legal, ethical and regulatory issues, case record form design, data collection, quality assurance and data auditing methodologies. The manuscript management system is completely online and includes a very quick and fair peer-review system, which is all easy to use. Visit http://www.dovepress.com/testimonials.php to read real quotes from published authors. 